\title{
Working Condition and Quality of Life for Female Workers in Garment Factories in Indonesia
}

\author{
Aryana Satrya $^{1}$, Permata Wulandari $^{1 *}$, Muthia Pramesti ${ }^{1}$, Sari Wahyuni ${ }^{1}$, M.Zuhdi ${ }^{1}$ \\ ${ }^{1}$ Department of Management, Faculty of Economics and Business, Universitas Indonesia \\ Email: permata.w@gmail.com
}

\begin{abstract}
Women are the dominant workers in garment industry in ASEAN region and worldwide. Notwithstanding the creation of jobs for women resulted by garment factories, workplaces employing women are often characterized by harsh working conditions. Their experience at the workplace affects their well-being, not only at work, but at home and as members of their households and communities. This research aimed to analyze how improvements in working conditions affect the lives of workers, especially women and their families. The research methodology used for this study is qualitative research, based on focus group discussion. It is conducted to several garment factories in Indonesia which are divided into factories which have previously joined better work programs in Indonesia (BWI factories) and factories which have not yet joined better work programs in Indonesia (Non-BWI factories). The analysis is classified into two dimensions: working conditions and individual context. The results show that working condition dimensions (compensation, giving birth, safety work, supervisor relationship, company's rules, promotion) and individual dimensions (objective of working, future achievement's and having more time at home) are better in the BWI factories compared to the non-BWI factories.
\end{abstract}

Type of Paper: Empirical

Keywords: competitive advantage, reputation, CSR, dynamic capability

\section{Introduction}

Empowerment of minority groups within organizations is a critical managerial and social issue in the recent decades, considering the ever more diversifying workforce in the current globalizing economy. The research's central underlying hypothesis is that when an organization has a structure (e.g., diversity climate etc.) that empowers people of various backgrounds and treats every employee justly (Laschinger et al., 2004), this leads to greater psychological empowerment among the employees (Conger and Kanungo, 1988). The researchers hypothesize that this would be the case for minorities (namely female workers) or those who are marginalized within the organization (Zhang and Bartol, 2010). This psychological empowerment would reinforce employees' self-perception that they have influenced over their tasks. Moreover, this condition will also improve work-life balance satisfaction (Abendroth and den Dulk, 2011), which in turn will improve work performance to pursue tasks. 
Worker participation in cooperative workplace problem-solving depends on a belief that grievance procedures are functional and effective. However, even if a functioning grievance procedure is available, a worker in a low power mindset may not engage with a grievance mechanism. A low power mindset and its impact on the capacity to act may have the broader consequence of altering the relative profitability of harsh and humane labor management practices.

In one laboratory experiment, participants were randomly assigned to high power and low power prompts (Galinsky et al., 2003). Participants assigned to the high-power prompt were asked to write about a time the participant had power over someone else. Participants assigned to the low power prompt were asked to write about a time someone else had power over them. The participant was then asked to complete additional tasks in another room. The participant was positioned so that a table fan was blowing on the participant, inhibiting the ability to complete the task. Of the participants placed in the high-power mindset, almost 70 percent turned off the fan. By comparison, of the participants placed in the low power mindset, only 42 percent reached over and turned off or moved the fan. Although there were no objective differences in how much power participants had in the situation, their power mindset significantly affected their decision to take an easily available and self-interested action that had no negative consequences for others.

The lack of a capacity to act can adversely affect a worker's ability to advocate on her own behalf. Miller (2014) studied the impact of a low power mindset on the relationship between human trafficking, working conditions, work effort and pay for migrant workers in Jordan. Workers who have been trafficked experience a loss of control and personal power. Empirically, trafficked workers exert more effort and accept lower pay when subjected to harsh treatment. By comparison, workers who believe they have work options exert less effort and require higher pay when subject to harsh treatment. Miller (2014) sorted Jordanian apparel factories into two categories: those that were found to be noncompliant on indicators of human trafficking by Better Work (BW), a joint program of the International Labor Organization (ILO) and the International Finance Corporation (IFC), and those for which there was no evidence of noncompliance. Workers in noncompliant factories were found to work harder and accept lower pay if they also reported abusive conditions of work. However, the relationship was reversed in compliant factories. The relative profitability of working conditions, then, depends importantly on a worker's mind set.

Similarly, Rubin et al. (2015) found that workers in Vietnamese apparel factories who report verbal and physical abuse by supervisors exhibit higher indicators of poor mental health, including a sense of hopelessness about the future. Asense of hopelessness is a negative predictor of productivity and wages (controlling for productivity and demographic characteristics). That is, workers who are the victims of verbal and physical abuse feel hopeless about the future, are less productive and receive lower pay (after controlling for the negative effect of verbal abuse on productivity).

The garment industry plays a dominant role in the employment opportunities for women throughout the ASEAN region. In 2014, ASEAN countries exported US \$21 billion worth of textiles and garments to the United States alone (U.S. Department of Commerce, 2014). Indonesia's garment sector can generally be classified as competitive and strong. Indonesia is ranked among the ten biggest garment supplier countries with the garment and textile industry 
significant contribution to the country's wealth. However, the nation garment and textile still far away from threatening China's dominant position as they control about $35 \%$ of global textile markets, while Indonesia controls only about 2\% (Indonesia Investment, 2016).

Ministry of Industry recorded that production of the textile industry and textile products or TPT with garment sector in it, is capable to meet $70 \%$ of domestic clothing needs. TPT sector also accounted for export surplus amounted for USD 4.31 billion in 2015 (Bisnis Indonesia, 2016). Garment industry was contributing 1.56\% GDP of Indonesia total GDP in 2012 with its export contribution reaching $8.6 \%$ in 2010 . It became an important resource to Indonesian government because of some strong evidence that the investment and exports are continues to rise. This type of workplace employs many workers that nearly 2 million Indonesians in 2011 (Stotz, 2015).

Market for garment from Indonesian was $1.7 \%$ in 2005 and increased to $2.9 \%$ globally. The value of garment being exported was 12.1 billion USD in 2011 or equivalent to 9.5 billion EUR. In 2011, there were 2,980 garment factories and 90\% of the factories are located on Java Island (Stotz, 2015). In 2016, new plants of garment industry were blooming, especially in Central Java (Bisnis Indonesia, 2016).

Women make up the majority of workers in the garment industry in the ASEAN region and worldwide. While garment factories in developing countries create employment opportunities particularly for women, workplaces employing women are often characterized by harsh working conditions. Their experience at the workplace affects well-being, not only at work, but at home and as members of their households and communities.

Existing evidence suggests that better work has had a significant impact on wages and work outcomes. Prior to the Cambodian-US Trade Agreement and the Better Factories Cambodia (BFC) program, apparel wage differentials were low. Robertson (2011) found that after the trade agreement wage differentials increased dramatically, and as predicted by trade theory, they follow changes in unit values of apparel. BFC targeted the working conditions to not experience a decline following a drop in the unit prices of apparel. Instead, they increase over this period (at a decreasing rate). These results are consistent with the hypothesis that BFC managed to maintain rising working conditions in the face of falling unit prices. Wages adjusted downward, but compliance increased suggesting that BFC's mission was successful.

Non-experimental evidence indicates that Better Work improves mental health. Domat et al. (2013) analyzed manager and worker survey data from Better Work Vietnam Monitoring and Evaluation collected between January 2010 and August 2012, find that working conditions have a significant positive impact on global life assessment and measures of depression and traumatic stress. The conjecture that factory managers may not be offering a cost-minimizing configuration of compensation and workplace amenities is tested.

There exist significant deviations of manager perceptions of working conditions from those of workers and these deviations significantly impact a worker's perceptions of wellbeing and indicators of mental health. Such deviations may lead the factory manager to under-provide certain workplace amenities relative to the cost-minimizing configuration. A common belief among apparel factory managers reported in case study analysis is that workers value money wages above workplace amenities, a finding corroborated by the statistical analysis. However, 
the analysis also indicates that manager perceptions do not reflect underlying worker values but rather a failure to effectively implement workplace innovations.

The research is designed to generate greater understanding of how improvements in working conditions affect the lives of workers, especially women, and their families. The research contrasting working condition, objective of working, giving birth, safety work, supervisor relationship, company's rules, future achievement's, promotion, and having more time at home between BWI factories and Non-BWI factories.

\section{Working Condition and Work-life Balance}

\section{Working condition}

In general, working conditions have broad coverage that includes various topic and issues. According to Better Work, working conditions are measured by gathering the workers' perception and firm's perspective in order to make it more realistic (Domat et al., 2013). In practice, factory-level compliance reports often to be used as a tool to measure working conditions. The practice of labor employment is usually below the standard and known as a poor labor practices. Based on International Labor Organization's (ILO) Working Conditions Laws Report, the working conditions are, including and not limited to, working hours, annual leave, maternity protection, minimum wage, amenities, physical environment, the degree of safety or danger, and the like that exist in the workplace. Other literature interprets working conditions more broadly that includes compliance with national laws and international norms or defined as ILO conventions (Robertson et al., 2016).

From the previous analysis, working condition is divided into interrelated four clusters: compensation, contracts and human resources, occupational safety and health, and working hour. The indicator for clusters include the information on wages, regularity of pay, information provided to workers, pay structure, training, verbal and physical abuse, sexual harassment, working time, issues related to freedom of association and collective bargaining, occupational health and safety and health services provided by the factory on Better Workprogram.

Low wages, long working hours, high temperature, excessive noise, poor air quality, unsanitary conditions, and abuse (both verbal and physical) are often cited as evidence of "sweatshops" characteristic production. Harsh working conditions in apparel factories became a large and growing debate about globalization and labor standards (Arbor \& Stern, 2005). Good work environment which includes wages, working hours, autonomy, and communication will have impact on work efficiency, effectiveness, productivity and the like that applies to bad work environment as well (Raziq \& Maulabakhsh, 2015). Robert Half International found working environment is a crucial factor that will impact to the workers' satisfaction (as cited on Lawson, 2012).

A research about assessing the sweatshop factory conditions in Vietnam towards firm profitmaximization by Brown et al. (2015) found that working conditions had a positive effect on the worker's productivity, where the productivity gains can increase the production. This result, as Domat et al. (2013) study appears to be an all win condition, for worker and employer, in that compliance of working conditions and has a positive impact on productivity which is shared with workers in the form of higher wages, increases firm profits and delivers higher 
productivity to buyers (Domat et al., 2013).

Previous researches from Better Work program presents the collection of related information about garment industry's working conditions that allows further research to have better understanding about the problems perceived by the workers. The recent research of Better Work in Indonesia with cooperation of government, and other related stakeholders found that there were many problems about working condition in Indonesian garment industrial sector (Better Work Indonesia, 2015).

The evidence of the research regarding factory working conditions about discrimination which became the challenge in fulfilling national requirements for workers with disabilities, occupational health and safety related issues, emergency situations, health services and first aid readiness, compensation with the overtime payment issues, and the incorrect use of nonpermanent contracts (Better Work Indonesia, 2015). However, due to time limitation and main issue of the garment labor, this research only focused on examining compensation and working hours.

\section{Work-life Balance}

Many researchers has attracted more interest with work-life balance in everyday discourses (Haar et al., 2014). Work-life balance is defined as the reflection of a person's orientation on their various roles, with respect to other social actors implicated in such roles (Tausig \& Fenwick, 2001). Work-life balance primarily emerged as woman based issue in the early 1970s (Rantanen et al., 2011). Considering the fact of female workers had difficulties in balancing their time for work and family responsibilities. Changes in worker's place of work and demographics have led to the escalation of concern to the problem among roles, worker and outside work lives. In 1980s, the focus of this issue was shifted towards the development of effective policies for work-life balance for both male and female workers.

According to Marks and MacDermid (1996), role balance is a behavioral pattern of acting across roles in a certain way and a corresponding cognitive-affective pattern of organizing one's inner life of multiple selves. Positive nor negative role balance are the two results on multiple roles engaged according to them. Positive role balance, in Marks and McDermid's theory, refers to the tendency to engage in every role with equally high effort, devotion, attention and care, whereas negative role balance refers to the tendency to engage in roles with apathy, cynicism, low effort and low attentiveness.

The ideal work-life balance condition is different for every person and might change over the time. Workers will acquire balance in their work-life condition when they harmonize the need of their paid employment with those related to private and family life. Consistent with theoretical advancement from previous research about work-life balance, is defined as being an individual's assessment of how good a person can balance their multiple life roles (Haar et al., 2014)

\section{Research Methodology}

Data was collected from garment workers in Indonesia. The study conducted with worker focus groups to identify the issues important to apparel workers in Indonesia. Prior to survey 
design, a selection of workers in Indonesia apparel factories were invited to participate in some focus group discussions (FGD). FGD was conducted in May 2017, in Jakarta and Cianjur. The companies were composed by 5 companies, under BWI and non-BWI factories.f The results explained comparison between both of BWI and non BWI factories. The purpose of the focus group is identifying participant concerns, work experiences and characterizations of topics under study. The results were being analyzed using qualitative analysis. The samples that involved in this study are 37 participants, whereas 9 participants are from a factory that was involved in BWI and 28 participants are from non BWI factories. The aspects were explored the areas of working condition (compensation, giving birth, safety work, supervisor relationship, company's rule and promotion) and individual context (objective of working, having time at home, future life achievement).

\section{Results and Discussion}

\section{Working Condition Dimension}

Based on International Labor Organization's (ILO) Working Conditions Laws Report, the working conditions are, including and not limited to, working hours, annual leave, maternity protection, minimum wage, amenities, physical environment, the degree of safety or danger, and the like that exist in the workplace. Other literature interprets working conditions more broadly that includes compliance with national laws and international norms or defined as ILO conventions (Robertson et al., 2016).

\section{Compensation}

In non-BWI factories, wage level does not meet regional minimum wages, therefore, the workers must work overtime to get additional income. While in BWI factories, the workers are being paid more than regional minimum wages standard. In non-BWI factories the supervisors assigned the workers additional works due to additional order/target or rework some mistakes. In contrast, supervisors in BWI companies have calculated the number of workers to meet workloads, therefore, they rarely have to do extra works. Both the BWI and non-BWI companies stated that the workers could reject the additional work hours by giving some reasons, but they were rarely voiced their objections to conduct the overtimes to gain more money. The workers also received salary once in two weeks in non-BWI factories and monthly payment in BWI companies. As a consequence, in non BWI companies, if the workers is absent, they will never receive payment for that day, even the reason is sickness or work accident while this situation will have no impact in BWI factories.

Both BWI and non BWI companies will provide them training before started their work. Unfortunately, in non-BWI companies, their salaries at probationary period were only paid in half, because the company needs to put it in the deposit account as personal guarantee. If the workers stopped working, the company would return it back. After one month, workers will get their full payment, even during their training period. But, this situation is not occurred in BWI companies. Workers have also faced delay on target production because machinery breakdown. If they have trouble with sewing machinery, they can complain to the mechanics, but the response is a little bit slow. In BWI companies, there are good mechanisms of giving complaints to supervisors. Working hours in BWI factories is shorter than non-BWI factories. 


\section{Giving birth}

In giving birth aspects, there are contrast practices between the BWI and non-BWI factories. In non BWI factories, the company does not give maternity leave, so if the worker in in maternity process, they have to exit the company and they need to re-apply again to have the same position like before. The company did not bear the birth cost. Most of them have 1-3 children. One senior lady has 4 children. BWI factory provides paid-leave for three months to comply with labor regulations. The company has paid the premium for compulsory state insurances, therefore the insurance covers the birth costfor up to 3 children for each worker.

\section{Safety work}

In BWI factories, zero accident program was implemented in the company. Therefore, work accidents, such as needle hurt did not ccur in the company. It is because the workers complemented with safety equipment that prevent hands from getting hurt by needle. The company also provides clinics for all workers. There are two midwives stand by in the clinics. Operator, helper and sewing need to stand for 8 hours. However, if the workers pregnant, the company provides chair. In contrast, the practice in non-BWI factories shows that the company didn't give protection for workers, thus safety for workers was very poor. Accident was still occurred because the lack of safety procedure. It is because the workers are not equipped with safety equipment that prevent hands from getting hurt by needle. The company doesn't provide clinic, neither the doctor o medical support are available in the factory. It will bring the worker to clinic nearby if they suffer from accident. However, if the workers pregnant, the company provides chair. Personal and family health insurances are covered by the company. To avoid accident, they will work more carefully.

\section{Supervisor relationship}

Both of BWI and non-BWI factories said that sexual harassment never occurred in the company. However, in non-BWI factories, the supervisor sometimes did some verbal harassment, but it's still related to work. The supervisor sometime acts a little rude in giving guidance to workers, especially when they did some mistake on the production. However, normally, they felt that they are like family who help each other. Workers also sometimes asking help from the supervisor, to lend them some money, for their personal need and emergency. Workers prefer to have male supervisor since they are less talk-active and can more empathy to understand female workers' problem. If workers have problems, they told to the supervisor directly by the individual basis. In BWI factories, there is some suggestion box which given to Human resource department and answer directly in the information wall. There is also meeting every Tuesday and Thursday among the line. Sometimes, it is like briefing that everyone joint it

\section{Company's rules}

The regulation between BWI and non BWI companies are similar. The workers cannot bring any kind of food and colored drink, mobile phone, jacket during their working time in the production site. They must put in locker outside the production site. Mineral water is allowable to bring to the site. An additional in non BWI companies is the employees must finish 50 units per day. If it is lower than that, workers need add more time for over time 


\section{Promotion}

In non-BWI, possibility for promotion is very low. The only possibility is to be a supervisor in the future, if a worker has a very excellence performance at work. However, there's unclear information about time and how to get promotion. Most possible promotion is from helper to be a sewer. Contrasting, performance based evaluation is used in the BWI factories. It is clear how to get promotion.

\section{Individual Context}

Objective of working

Both BWI and non-BWI workers have the same objectives. The objective of working is mainly to fulfill primary needs. It is because salary from husband is enough for food only. The workers save money for children future education and home decoration. Besides, the other objective of working is to fulfill motorcycle instalment and another instalment. They do not have debt for primary needs. They have debt to cover secondary needs. There are saving that arranged by supervisor every month. From non-BWI workers, they also want to have better fortune in the future. They want to have private residence, small business (sell things in a store, being tailor) and continue their study to the university. Apart of that, they thought that they want to have external activities, rather than only stay at home and do nothing.

\section{Have more time at home}

The workers said no differences in term of busy because company always add more employees for extra work in BWI factories. However, in non-BWI factories the workers said didn't have time to be with family and friends during the workdays. Sometimes, they also work during the weekend as well, thus it reduces their personal time for family and friends. They also need to finish household work during the remaining time in weekend. Both of BWI and non-BWI workers said that mother in law or relatives take care to workers' children. Most of them used contraception except single parent. Supervisor did not restrict to number of children. Many of supervisors have many kids.

\section{Future achievements}

The workers in BWI and non BWI factories want to have more fortune in the future byhaving small business, getting married with rich guy, having higher education, having private residence. However, the bonus is very rare.

As a summary, figure 1 shows a comparative condition between non BWI and BWI factories. 

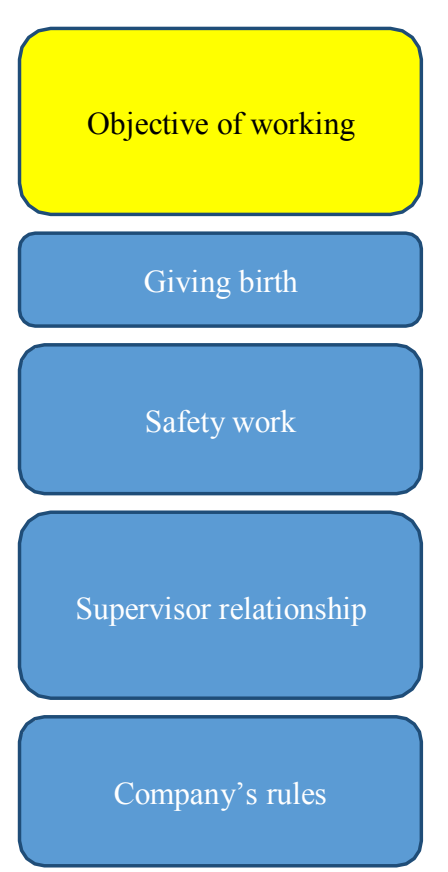

Future life objective

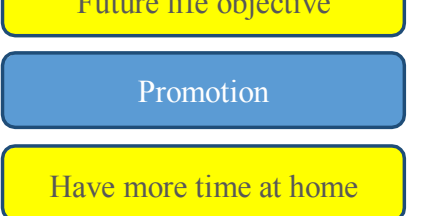

Additional work for additional order

Forthnight/ bi-weekly salary

No salary payment for worker's absent

Unpaid probationary period

Pay deposit fee to employer as guarantee

Slow respond for every machinery breakdown

- Working hours: 07.30 am to $17.30 \mathrm{pm}$

- No insurance and social security

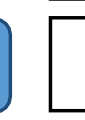

- Fulfill basic needs

Better fortune in the future

- Having external activity

No maternity leave

Birth cost not covered

\begin{tabular}{|ll|}
\hline- & No worker safety protection \\
- & Lack of safety procedure, no inhouse clinics, no chair for \\
pregnant workers
\end{tabular}

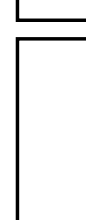

- No sexual harassment

- Some verbal harassment related to work

- Grievance handling: talk directly to supervisor
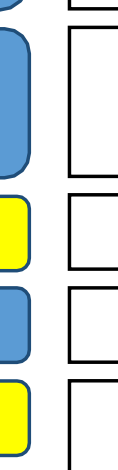

Garment company standard regulations

- Target: 50 units per day $\rightarrow$ unpaid overtime if not achieved

\begin{tabular}{|ll|}
\hline - & Having small business as entrepreneur \\
\hline - & Promotion is rarely occurs \\
\hline - & Rare; Mother taking care of children \\
\hline
\end{tabular}

Pay meet regional minimum wage level

- $\quad$ Rarely additional work

- Monthly salary

- If there is reason for absent $=>$ full payment

Three months probationary period with full paid salary

- No deposit fee to factories as guarantee

- Supervisor always maintain any staff problems

- Working hours: $07.30 \mathrm{am}$ to $16.30 \mathrm{pm}$

- Compulsory state insurance paid by employers

- $\quad$ Fulfill basic needs

- Better fortune in the future

- Pay loan provided by supervisor

\begin{tabular}{|c|}
\hline $\begin{array}{l}\text { - } \quad 3 \text { months paid-leave } \\
\text { - } \quad \text { Compulsory employers' paid insurance covers birth cost }\end{array}$ \\
\hline $\begin{array}{ll}\text { - } & \text { Zero accident } \\
\text { - } & \text { Safety procedure, in-house clinics provided, chair provided } \\
\text { for pregnant workers }\end{array}$ \\
\hline
\end{tabular}

\begin{tabular}{ll}
\hline & No sexual and verbal harassment \\
- & $\begin{array}{l}\text { Grievance handling: suggestion box to human resource } \\
\text { department, line weekly meeting with supervisor }\end{array}$
\end{tabular}

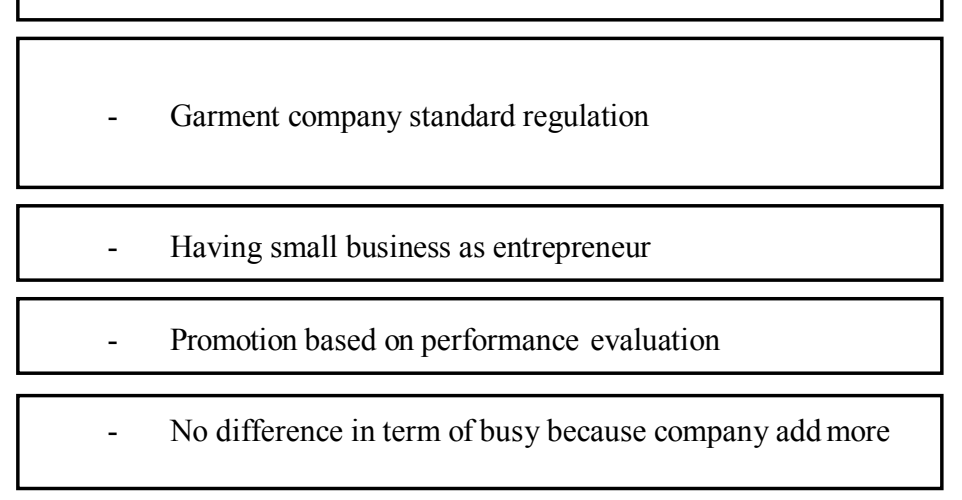

Working Condition Context

BWI Training

Individual Context

Figure 1. Comparing Between Non BWI and BWI Factories 


\section{Implication \& Conclusion}

There are some similarities on the differences dimensions between company under BWI and non BWI. Similarities were captured in the individual context dimensions of objective of work, future achievement, and time availability at home. The differences were found in the dimensions of compensation, safety work, giving birth, supervisor's relationship, company's rule and promotion. It indicates that the interventions of the BWI program have improved the worker's conditions at the working place.

According to the results, there are some implications which need to be considered to improve the current situation. First, non-BWI workers had less balance in works and life comparing to BWI workers, since they received less payment, less job security, less workplace safety, and less mutual policy. Second, welfare was less accepted by non-BWI workers, in which indicated by lower payment, comparing to the BWI workers. Third, both BWI and non-BWI workers were concerning the working condition to be improved, when they are asking about the future fortune.

This study is a qualitative study based on FGD, in which it needs some other supporting research to explain about the relationship between working condition and work life balance in garment factories in Indonesia.

\section{References}

Abendroth, A.K. and den Dulk, L.. (2011). Support for the Work-Life Balance in Europe: The Impact of Workplace, and Family Support on Work-Life Balance Satisfaction. Work, Employment, and Society, No. 2, pp. 234-256.

Aisha, A. N., \& Hardjomidjojo, P. (2013). Effects of working ability, working condition, motivation and incentive on employees' multi-dimensional performance. International Journal of Innovation, Management and Technology, 4(6), 605-609.

Albertsen, K., Rafnsdóttir, G. L., Grimsmo, A., Tomasson, K., \& Kauppinen, K. (2008). Workhours and worklife balance. Scandinavian Journal of Work, Environment \& Health, 34(5), 14-21.

Barrett, P. (2007). Structural Equation Modelling: Adjudging model fit. Personality and Individual Differences, vol. 42, pp. 815-824

Carnicer, M. P. D. L., Sánchez, A. M., Pérez, M. P., \& Jiménez, M. J. V. (2004). Work-family conflict in a southern European country: The influence of job-related and non-related factors. Journal of Managerial Psychology, 19(5), 466-489.

Conger, J.A. and R. N. Kanungo. 1988. The Empowerment Process: Integrating Theory and Practice. The Academy of Management Review, vol. 13 (3), pp. 471-482.

Domat, G., A. Adler, R. Dehejia, D. Brown and R. Robertson. (2013). Do Managers Know what Workers Want? Manager-worker information asymmetries and Pareto Optimal working conditions. Better Work Discussion Paper Series, No. 10. ILO, Geneva. 
Flavin, P., Pacek, A. C., \& Radcliff, B. (2010). Labor unions and life satisfaction: Evidence from new data. Social indicators research, 98(3), 435-449.

Gallie, D., \& Russell, H. (2009). Work-family conflict and working conditions in Western Europe. Social Indicators Research, 93(3), 445-467.

Galinsky, A. D., Gruenfeld, D. H., \& Magee, J. C. (2003). From power to action. Journal of Personality and Social Psychology, 85, 453-466.

Healy, G. N. (2013). Does an 'activity-permissive'workplace change office workers' sitting and activity time?. PLoS ONE, 8(10), e76723.

Hair, J. F, W. C. Black, B. J. Babin, R.E. Anderson. (2010). Multivariate Data Analysis, New Jersey: Prentice Hall.

Kinnunen, U., \& Mauno, S. (1998). Antecedents and outcomes of work-family conflict among employed women and men in Finland. Human Relations, 51(2), 157-177.

Laschinger. H.A., J.E. Finegan, J. Jamian, and P. Wilk, P. (2004). A Longitudinal Analysis of the Impact of the Workplace Empowerment on Work Satisfaction. Journal of Organizational Behavior, vol. 25, pp. 527-545.

Lu, L., Kao, S. F., Chang, T. T., Wu, H. P., \& Cooper, C. L. (2008). Work/family demands, work flexibility, work/family conflict, and their consequences at work: A national probability sample in Taiwan. International Journal of Stress Management, 15(1), 111.

Mas-Machuca, M., Berbegal-Mirabent, J., \& Alegre, I. (2016). Work-life balance and its relationship with organizational pride and job satisfaction. Journal of Managerial Psychology, 31(2), 586-602.

Miller, M. (2014). Should I Stay or Should I Go? Analyzing the decision of the firm to impede worker return migration. Tufts University. Available at Proquest.

Newman, A., Nielsen, I., Smyth, R., \& Hooke, A. (2015). Examining the relationship between workplace support and life satisfaction: the mediating role of job satisfaction. Social indicators research, 120(3), 769-781.

Oswald, A. (2012). The effect of working environment on workers performance: the case of reproductive and child health care providers in Tarime district (Doctoral dissertation, Muhimbili University of Health and Allied Sciences).

Papia, M. J., \& Ruma, A. (2014). Impact of Occupational Risk Factors on the Woman Reproductive Health in Bangladesh: A Perspective. Journal of Commerce and Management Thought, 5(1), 47.

Robertson, R., Di, H., Brown, D., \& Dehejia, R. (2016). Working Conditions, Work Outcomes and Policy in Asian Developing Countries. ADB Eonomics Working Paper Series. 
Robertson, T. (2011). Apparel Wages Before and After Better Factories Cambodia. Better Work Discussion Paper Series No. 3, ILO, Geneva.

Robone, S., Jones, A. M., \& Rice, N. (2011). Contractual conditions, working conditions and their impact on health and well-being. The European Journal of Health Economics, 12(5), 429-444.

Rubin, J., Babbitt, L., Brown, D. and Dehejia, R.. (2015). Wages, hours and the cascade of noncompliance. In process. Tufts University.

Sankar, M. (2015). Impact of Hygiene Factors in Employee Retention: Experimental Study on Paper Industry. Indian Journal of Management Scienc, 5(1), 58-61.

Schewe, P., Riger, S., Howard, A., Staggs, S. L., \& Mason, G. E. (2006). Factors associated with domestic violence and sexual assault victimization. Journal of Family Violence, 21(7), 469-475.

Sengupta, S., \& Dev, S. (2013). What makes employees stay? Exploring the dimensions in context of urban-centric business process outsourcing industry in India. Strategic Outsourcing: An International Journal, 6(3), 258-276.

Tabatabaei, S., Hosseinian, S., \& Gharanjiki, B. (2011). General health, stress associated to the work and job satisfaction of Hormozgan Cement Factory employees in Iran. Procedia-Social and Behavioral Sciences, 30, 1897-1901.

Umamaheswari, S., \& Krishnan, J. (2016). Work force retention: Role of work environment, organization commitment, supervisor support and training \& development in ceramic sanitary ware industries in India. Journal of Industrial Engineering and Management, $9(3), 612-633$.

U.S. Department of Commerce, Office of Textiles and Apparel. (2015). Textile \& Apparel Trade Balance Report. http://otexa.trade.gov/tbrimp.htm

Wettersten, K. B., Rudolph, S. E., Faul, K., Gallagher, K., Trangsrud, H. B., Adams, K., Graham, S. \& Terrance, C. (2004). Freedom Through Self-Sufficiency: A Qualitative Examination of the Impact of Domestic Violence on the Working Lives of Women in Shelter. Journal of Counseling Psychology, 51(4), 447-462.

Zhang, X. and K.M. Bartol. 2010. The Influence of Creative Process Engagement on Employee Creative Performance and Overall Job Performance: A Curvilinear Assessment. Journal of Applied Psychology, vol. 95 (5), September. 